Pacific Journal of Mathematics

ON EXTREME POINTS OF THE JOINT NUMERICAL RANGE 


\title{
ON EXTREME POINTS OF THE JOINT NUMERICAL RANGE OF COMMUTING NORMAL OPERATORS
}

\author{
Pushpa JuneJA
}

Let $W(T)=\{\langle T x, x\rangle:\|x\|=1 ; x \in H\}$ denote the numerical range of a bounded normal operator $T$ on a complex Hilbert space $H$. S. Hildebrandt has proved that if $\lambda$ is an extreme point of $\overline{W(T)}$, the closure of $W(T)$, and $\lambda \in W(T)$ then $\lambda$ is in the point spectrum of $T$. In this note, we shall prove an analogous result for an $n$-tuple of commuting bounded normal operators on $H$.

2. Notations and terminology, Let $A=\left(A_{1}, \cdots, A_{n}\right)$ be an $n$-tuple of commuting bounded operators on $H$ and $\mathscr{U}$, the double commutant of $\left\{A_{1}, \cdots, A_{n}\right\}$. Then $\mathscr{W}$ is a commutative Banach algebra with identity, containing the set $\left\{A_{1}, \cdots, A_{n}\right\}$. We shall need the following definitions [3] and [4].

A point $z=\left(z_{1}, \cdots, z_{n}\right)$ of $\mathscr{C}^{n}$ is in the joint spectrum $\sigma(A)$ of $A$ relative to $\mathscr{C}$ if for all $B_{1}, \cdots, B_{n}$ in $\mathscr{U}$

$$
\sum_{j=1}^{n} B_{j}\left(A_{j}-z_{j}\right) \neq I \text {. }
$$

The joint numerical range of $A$ is the set of all points $z=\left(z_{1}, \cdots, z_{n}\right)$ of $\mathscr{C}^{n}$ such that for some $x$ in $H$ with $\|x\|=1, z_{j}=\left\langle A_{j} x, x\right\rangle$ i.e.,

$$
W(A)=\left\{\langle A x, x\rangle=\left(\left\langle A_{1} x, x\right\rangle, \cdots,\left\langle A_{n} x, x\right\rangle\right)\right\} .
$$

We say that $z=\left(z_{1}, \cdots, z_{n}\right)$ is in the joint point spectrum $\sigma_{p}(A)$ if there exists some $0 \neq x \in H$ such that

$$
A_{j} x=z_{j} x, \quad j=1, \cdots, n,
$$

and that $z$ is in the joint approximate point spectrum $\sigma_{\pi}(A)$ if there exists a sequence $\left\{x_{n}\right\}$ of unit vectors in $H$ such that $\left\|\left(A_{j}-z_{j}\right) x_{n}\right\| \rightarrow 0$ as $n \rightarrow \infty, j=1, \cdots, n$.

Bunce [2] has proved that $\sigma_{\pi}(A)$ is a nonempty compact subset of $\mathscr{C}^{n}$.

If $A=\left(A_{1}, \cdots, A_{n}\right)$ is an $n$-tuple of commuting normal operators, then the extreme points of $\overline{W(A)}$ are in the joint approximate point spectrum $\sigma_{\pi}(A)$. This is immediate from the fact that for such $A_{j}$ 's,

$$
\begin{aligned}
\overline{W(A)} & =\text { closed convex hull of } \sigma(A) \\
& =\text { closed convex hull of } \sigma_{\pi}(A),
\end{aligned}
$$

and that every compact set contains the extreme points of its closed 
convex hull [1, Cor. 36.11 , p. 144]. We show in the following theorem that something more can be said about the extreme points of $\overline{W(A)}$, see Hildebrandt [5].

THEOREM. Let $A=\left(A_{1}, \cdots, A_{n}\right)$ be an n-tuple of commuting normal operators on $H$. If $\lambda=\left(\lambda_{1}, \cdots, \lambda_{n}\right)$ is an extreme point of $\overline{W(A)}$ and $\lambda \in W(A)$, then $\lambda \in \sigma_{p}(A)$.

Proof. Firstly, we shall prove the result for commuting selfadjoint operators.

It is sufficient to show that if $(0, \cdots, 0)$ is an extreme point of $\overline{W(A)}$ and $(0, \cdots, 0) \in W(A)$, then $(0, \cdots, 0) \in \sigma_{p}(A)$.

Since $(0, \cdots, 0)$ is an extreme point of $\overline{W(A})$, we may assume that

$$
\overline{W(A)} \subset\left\{z=\left(\alpha_{1}, \cdots, \alpha_{n}\right) \in \mathscr{C}^{n} ; \operatorname{Re} \alpha_{n} \geqq 0\right\} .
$$

As $A_{1}, \cdots, A_{n}$ are commuting self-adjoint operators, there exists a measure space $(X, \mu)$ and a set of bounded measurable functions $\phi_{1}, \cdots, \varphi_{n}$ in $L^{\infty}(X, \mu)$ such that each $A_{j}$ is unitarily equivalent to multiplication by $\varphi_{j}$ on $L^{2}(X, \mu)$. Thus

$$
A_{j} f=\varphi_{j} f, \text { for all } f \in L^{2}(X, \mu)
$$

and for each $j=1,2, \cdots, n[3]$.

Because of the assumption (1), and since $\sigma(A) \subset \overline{W(A)}$, we have

$$
\sigma(A) \subset\left\{z=\left(\alpha_{1}, \cdots, \alpha_{n}\right) \in \mathscr{C}^{n} ; \operatorname{Re} \alpha_{n} \geqq 0\right\} .
$$

It follows that $A_{n} \geqq 0$ and so $\varphi_{n}(x) \geqq 0$ a.e. Let, if possible, $(0, \cdots, 0) \notin \sigma_{p}\left(A_{1}, \cdots, A_{n}\right)$. Then $\left|\varphi_{j}(x)\right|>0$ a.e. for at least one $j=$ $1,2, \cdots, n$. Let

$$
E_{1}=\left\{x \in X ; \operatorname{Im} \varphi_{j}(x) \geqq 0\right\}
$$

and

$$
E_{2}=\left\{x \in X ; \operatorname{Im} \varphi_{j}(x)<0\right\} .
$$

Since $(0, \cdots, 0) \in W\left(A_{1}, \cdots, A_{n}\right)$, for some $f \in H$ with $\|f\|=1$, $\left\langle A_{j} f, f\right\rangle=0, j=1,2, \cdots, n$ and

$$
\begin{aligned}
0=\left\langle A_{j} f, f\right\rangle & =\int_{X} \varphi_{j}(x)|f(x)|^{2} d \mu \\
& =\int_{E_{\mathrm{\imath}}} \varphi_{j}|f|^{2} d \mu+\int_{E_{2}} \varphi_{j}|f|^{2} d \mu \\
& =\int_{X} \varphi_{j}\left|\chi_{E_{1}} f\right|^{2} d \mu+\int_{X} \varphi_{j}\left|\chi_{E_{2}} f\right|^{2} d \mu
\end{aligned}
$$




$$
\begin{aligned}
& =\int_{X} \varphi_{j}\left|g_{1}\right|^{2} d \mu+\int_{X} \varphi_{j}\left|g_{2}\right|^{2} d \mu \\
& =\left\langle A_{j} g_{1}, g_{1}\right\rangle+\left\langle A_{j} g_{2}, g_{2}\right\rangle,
\end{aligned}
$$

where $g_{k} x=(\chi)_{E_{k}}(x) f(x), k=1,2, \chi$ denotes the characteristic function. As $A_{n} \geqq 0$ and $\left\langle A_{n} g_{1}, g_{1}\right\rangle+\left\langle A_{n} g_{2}, g_{2}\right\rangle=0$, it follows that $\left\langle A_{n} g_{1}, g_{1}\right\rangle=0$ and $\left\langle A_{n} g_{2}, g_{2}\right\rangle=0$.

(i) Suppose that $\left|\varphi_{n}(x)\right|>0$ a.e. Then $\left\langle A_{n} g_{1}, g_{1}\right\rangle=0$ implies that $f$ and $\varphi_{n}$ have complementary support which is a contradiction to the fact that $\|f\|=1$ and $\left|\varphi_{n}(x)\right|>0$ a.e.

(ii) If $\left|\varphi_{j}(x)\right|>0$ a.e for $j \neq n$, then $\left\langle A_{j} g_{1}, g_{1}\right\rangle \neq 0$ for if $\left\langle A_{j} g, g_{1}\right\rangle=0$, then $\left\langle A_{j} g_{2}, g_{2}\right\rangle=0$ which means that $f$ and $\varphi_{j}$ have complementary support which is again not possible as argued in (i). Thus $\left\langle A_{j} g_{1}, g_{1}\right\rangle \neq 0,\left\langle A_{j} g_{2}, g_{2}\right\rangle \neq 0$. We write $h_{k}(x)=g_{k}(x) /\left\|g_{k}\right\|, k=$ 1,2 and

$$
\lambda=\left\{\left\langle A_{1} h_{1}, h_{1}\right\rangle, \cdots,\left\langle A_{n} h_{1}, h_{1}\right\rangle\right\}
$$

and

$$
\mu=\left\{\left\langle A_{1} h_{2}, h_{2}\right\rangle, \cdots,\left\langle A_{n} h_{2}, h_{2}\right\rangle\right\} .
$$

Thus $\lambda$ and $\mu$ are two points in the joint numerical range with $(0, \cdots, 0)$ as an interior point of the line segment joining these two, which is a contradiction. This proves the result for commuting selfadjoint $A_{j}$ 's.

Now, we consider $A_{j}$ 's to be commuting normal operators on $H$. Since each $A_{j}$ has a unique decomposition

$$
A_{j}=A_{j_{1}}+i A_{j 2}, \quad j=1,2, \cdots, n,
$$

where $A_{j_{1}}$ and $A_{j 2}$ are self-adjoint, the $2 n$-tuple

$$
\left\{A_{11}, A_{21}, \cdots, A_{n 1}, A_{12}, \cdots, A_{n 2}\right\}
$$

is of commuting self-adjoint operators. Similarly if

$$
\lambda_{j}=\lambda_{j_{1}}+i \lambda_{j_{2}}, \quad j=1,2, \cdots, n
$$

then $\lambda^{\prime}=\left\{\lambda_{11}, \cdots, \lambda_{n 1}, \lambda_{12}, \cdots, \lambda_{n 2}\right\}$ is an extreme point of $\overline{W\left(A_{11}, \cdots, A_{n 2}\right)}$ and $\quad \lambda^{\prime} \in W\left(A_{11}, \cdots, A_{n 2}\right)$. Thus $\lambda^{\prime} \in \sigma_{p}\left(A_{11}, \cdots, A_{n 2}\right)$. Hence $\lambda=$ $\left(\lambda_{1}, \cdots, \lambda_{n}\right) \in \sigma_{p}\left(A_{1}, \cdots, A_{n}\right)$ and the result is proved.

The author wishes to thank Professor B. S. Yadav for his help in the preparation of this paper.

\section{REFERENCES}

1. S. K. Berberian, Lectures in Functional Analysis and Operator Theory, SpringerVerlag, York. 
2. J. Bunce, The joint spectrum of commuting non-normal operators, Proc. Amer. Math. Soc., 29 (1971), 499-505.

3. A. T. Dash, Joint spectra, Studia Math., XLV (1973), 225-237.

4. - Joint numerical range, Glasnik Matematicki, 7 (27) (1972), 75-81.

5. S. Hildebrandt, Über den numerischen Wertebereich eines operators, Math. Annalen, 163 (1966), 230-247.

6. C. R. MacCluer, On extreme points of the numerical range of normal operators, Proc. Amer. Math. Soc., 16 (1965), 1183-1184.

Received June 15, 1976.

UNIVERSITY OF DELHI 


\section{PACIFIC JOURNAL OF MATHEMATICS}

\section{EDITORS}

RICHARD ARENS (Managing Editor)

University of California

Los Angeles, California 90024

\section{J. DugunduI}

Department of Mathematics University of Southern California Los Angeles, California 90007

D. Gilbarg and J. Milgram

Stanford University

Stanford, California 94305

\author{
R. A. Beaumont \\ University of Washington \\ Seattle, Washington 98105
}

\section{ASSOCIATE EDITORS}
B. H. NeUmanN
F. WOLF
K. YosHIDA

\section{SUPPORTING INSTITUTIONS}

\author{
UNIVERSITY OF BRITISH COLUMBIA \\ CALIFORNIA INSTITUTE OF TECHNOLOGY \\ UNIVERSITY OF CALIFORNIA \\ MONTANA STATE UNIVERSITY \\ UNIVERSITY OF NEVADA \\ NEW MEXICO STATE UNIVERSITY \\ OREGON STATE UNIVERSITY \\ UNIVERSITY OF OREGON \\ OSAKA UNIVERSITY
}

\author{
UNIVERSITY OF SOUTHERN CALIFORNIA \\ STANFORD UNIVERSITY \\ UNIVERSITY OF HAWAII \\ UNIVERSITY OF TOKYO \\ UNIVERSITY OF UTAH \\ WASHINGTON STATE UNIVERSITY \\ UNIVERSITY OF WASHINGTON \\ AMERICAN MATHEMATICAL SOCIETY
}

The Supporting Institutions listed above contribute to the cost of publication of this Journal, but they are not owners or publishers and have no responsibility for its content or policies.

Mathematical papers intended for publication in the Pacific Journal of Mathematics should be in typed form or offset-reproduced, (not dittoed), double spaced with large margins. Please do not use built up fractions in the text of your manuscript. You may however, use them in the displayed equations. Underline Greek letters in red, German in green, and script in blue. The first paragraph or two must be capable of being used separately as a synopsis of the entire paper. Items of the bibliography should not be cited there unless absolutely necessary, in which case they must be identified by author and Journal, rather than by item number. Manuscripts, in triplicate, may be sent to any one of the editors. Please classify according to the scheme of Math. Reviews, Index to Vol. 39. All other communications should be addressed to the managing editor, or Elaine Barth, University of California, Los Angeles, California, 90024.

The Pacific Journal of Mathematics expects the author's institution to pay page charges, and reserves the right to delay publication for nonpayment of charges in case of financial emergency.

100 reprints are provided free for each article, only if page charges have been substantially paid. Additional copies may be obtained at cost in multiples of 50 .

The Pacific Journal of Mathematics is issued monthly as of January 1966. Regular subscription rate: $\$ 72.00$ a year (6 Vols., 12 issues). Special rate: $\$ 36.00$ a year to individual members of supporting institutions.

Subscriptions, orders for back numbers, and changes of address should be sent to Pacific Journal of Mathematics, 103 Highland Boulevard, Berkeley, California, 94708.

PUBLISHED BY PACIFIC JOURNAL OF MATHEMATICS, A NON-PROFIT CORPORATION

Printed at Kokusai Bunken Insatsusha (International Academic Printing Co., Ltd.), 8-8, 3-chome, Takadanobaba, Shinjuku-ku, Tokyo 160, Japan. 


\section{Pacific Journal of Mathematics}

Patricia Andresen and Marvin David Marcus, Weyl's inequality and

quadratic forms on the Grassmannian .......................

George Bachman and Alan Sultan, Regular lattice measures: mappings and

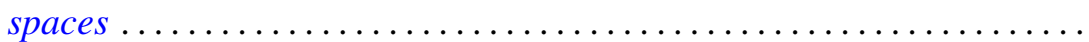

David Geoffrey Cantor, On certain algebraic integers and approximation by rational functions with integral coefficients ...................

James Richard Choike, On the value distribution of functions meromorphic in the unit disk with a spiral asymptotic value ..................

David Earl Dobbs, Divided rings and going-down................ 353

Mark Finkelstein and Robert James Whitley, Integrals of continuous

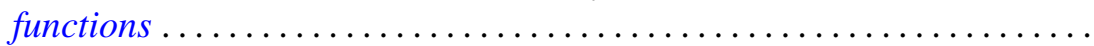

Ronald Owen Fulp and Joe Alton Marlin, Integrals of foliations on manifolds with a generalized symplectic structure ...............

Cheong Seng Hoo, Principal and induced fibrations .................

Wu-Chung Hsiang and Richard W. Sharpe, Parametrized surgery and

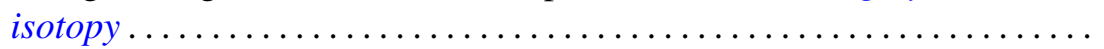

Surender Kumar Jain, Surjeet Singh and Robin Gregory Symonds, Rings whose proper cyclic modules are quasi-injective .................

Pushpa Juneja, On extreme points of the joint numerical range of commuting normal operators...

Athanassios G. Kartsatos, Nth order oscillations with middle terms of order $N-2$.

John Keith Luedeman, The generalized translational hull of a

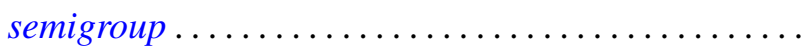

Louis Jackson Ratliff, Jr., The altitude formula and DVR's ...

Ralph Gordon Stanton, C. Sudler and Hugh C. Williams, An upper bound for the period of the simple continued fraction for $\sqrt{D}$...

David Westreich, Global analysis and periodic solutions of second order systems of nonlinear differential equations...

David Lee Armacost, Correction to: "Compactly cogenerated LCA

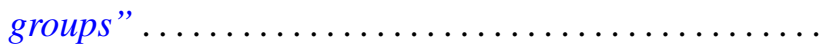

Jerry Malzan, Corrections to: "On groups with a single involution" .

David Westreich, Correction to: "Bifurcation of operator equations with unbounded linearized part" ...................... 